\title{
In situ measurement of lattice strains in mixed ceramic cutting tools under thermal and mechanical loads using synchrotron radiation
}

\author{
C. Eichenseer ${ }^{\mathrm{i}}$, I. Wittmann ${ }^{\mathrm{i}}$, C. Hartig ${ }^{\mathrm{ii}}$, G. A. Schneider ${ }^{\mathrm{iii}}$, N. Schell ${ }^{\mathrm{iv}}$, W. Hintze ${ }^{\mathrm{i}}$ \\ ${ }^{i}$ Hamburg University of Technology, Institute of Production Management and \\ Technology, Denickestr. 17, 21073 Hamburg, Germany
}

Phone: 0049 - $04-42878-3233$

Fax: $0049-04-42878-2295$

E-Mail: eichenseer@tuhh.de

${ }^{i i}$ Hamburg University of Technology, Institute of Materials Physics and Technology, Eißendorfer Str. 42, 21073 Hamburg, Germany

iii Hamburg University of Technology, Institute of Advanced Ceramics, Denickestr. 15, 21073 Hamburg, Germany

${ }^{i v}$ Helmholtz-Zentrum Geesthacht, Center for Materials- and Coastal Research, Institute of Materials Research, Max-Planck-Str. 1, 21502 Geesthacht, Germany

To completely understand wear mechanisms of mixed ceramic cutting tools $\left(\mathrm{Al}_{2} \mathrm{O}_{3}\right.$-TiC), residual stress states and the superposition of external loads during hard turning should be investigated.

This can be done via X-ray diffraction using high-energy synchrotron radiation to determine lattice strains in the material. For this reason, in first model tests, strain states in mixed ceramics were determined during the application of external loads. An experimental setup was developed to measure lattice strains in the different phases of the ceramic material in situ during thermal, mechanical and thermo-mechanical loading for first reference. The accuracy of the setup was sufficient to clearly determine shifts in lattice parameters in the different phases due to external loads. By applying a thermal load on the mixed ceramic material the two main phases showed different elastic lattice strains. Thus, a slightly lower coefficient of thermal expansion in the $\mathrm{Al}_{2} \mathrm{O}_{3}$-phase than in the $\mathrm{Ti}(\mathrm{O}, \mathrm{C})$-phase could be determined. This indicated the development of compressive stresses in $\mathrm{Al}_{2} \mathrm{O}_{3}$-phase and tensile stresses in $\mathrm{Ti}(\mathrm{O}, \mathrm{C})$-phase at room temperature. By applying external bending stresses to the mixed ceramic material, for both phases equal lattice strains could be determined. From these strains stresses could be calculated for both phases which were in the same order of magnitude as external stresses. With further in situ investigations of strain and stress states in the different phases of mixed ceramics during friction and turning experiments a more comprehensive characterization of wear mechanisms is possible.

Keywords: Mixed ceramics $\cdot$ In situ measurement $\cdot$ Synchrotron radiation $\cdot X$-ray diffraction · Stress state 


\section{Introduction}

Mixed ceramic cutting tools for hard turning applications must withstand high thermal and mechanical loads to manifest high wear resistance. During hard turning high cutting and radial forces act on small contact areas and thus lead to high stresses in the tool material [1]. At the same time high thermal loads with temperatures from $500{ }^{\circ} \mathrm{C}$ up to $1500{ }^{\circ} \mathrm{C}$ develop in the cutting zone because of high plastic deformation of the workpiece [2]. As a consequence high tool wear occurs. To investigate different wear mechanisms such as adhesion, abrasion, or tribooxidation, characterization is done mostly in terms of empirical testing, i.e. at varying cutting parameters wear development is observed via optical microscopy. For example, wear is recorded as a function of time at different parameters such as feed or cutting velocity [3-6]. From this data, models were developed to predict wear on the tool flank [7]. But still there are only a few investigations to date which analyze the relation between residual stress evolution, wear mechanisms and / or material failure in cutting tools. Despite this, it is known that with shot peening processes even brittle materials like ceramics can be strengthened by inducing compressive residual stresses in the surface layers [8]. In the field of layered ceramics, i.e. $\mathrm{Al}_{2} \mathrm{O}_{3} /(\mathrm{W}, \mathrm{Ti}) \mathrm{C}+\mathrm{Al}_{2} \mathrm{O}_{3} / \mathrm{TiC}$ - or Ti/TiAlN-multilayers, stresses occur due to different coefficients of thermal expansion. These stress states lead to enhanced wear and fracture resistance [9-12]. Also in alumina/zirconia micro/nanocomposites for biomedical applications Bartolomé et al. determined residual strain and stress distributions to gain a higher understanding of the materials wear mechanisms [13]. Gibmeier et al. reported that in indentation tests microhardness is highly affected by residual stresses [14]. Waikar et al. refers to tribology tests where residual stresses can easily occur in the same order of magnitude as external loads originating from Hertzian pressure or friction [15]. Thus, wear rate is linked to the development of residual stresses in a tribological system. In cutting tools internal stresses can be determined in the surface with the $\sin ^{2} \psi$-method using X-ray diffraction but no statement can be made on the superposition of thermo-mechanical loads during cutting processes. For this reason Hussainova et al. determined the stress states in cermets applying an analytical model and stated that with decreasing stresses in the cermet material erosion resistance is increased due to higher molybdenum content [12]. Also few investigations were done using finite element method to predict stress 
distributions on whisker reinforced ceramic cutting tools [16]. Regarding mixed ceramic cutting tools for hard turning applications the determination of the internal stress state is even more important as the material consists of two main phases, namely alumina $\left(\mathrm{Al}_{2} \mathrm{O}_{3}\right)$ and titanium oxycarbide $(\mathrm{Ti}(\mathrm{O}, \mathrm{C}))$, with small amounts of zirconia $\left(\mathrm{ZrO}_{2}\right)$. Fitzpatrick et al. stated that loads applied on composite materials tend to partition unequally between the phases because of a mismatch in stiffness [17]. Also thermal stresses develop upon changes in temperature due to different coefficients of thermal expansion of the phases. All this leads to the fact that for a complete understanding of wear mechanisms in mixed ceramic cutting tools, the internal stress and strain distribution and the superposition with external thermal and mechanical loads during hard turning should be investigated. The analysis of changes in stress state should be carried out in situ during cutting and tribology testing using high-energy synchrotron radiation. The aim of this paper is to show first results and a setup to investigate residual stress states in mixed ceramics in first model tests. Thus, for first reference, an experimental setup was developed to record the effects of external thermal and mechanical loads on the lattice strains in mixed ceramics using synchrotron radiation at the PETRA III beamline P07, DESY, Hamburg.

\section{Experimental}

\subsection{Setup for the application of thermal and mechanical loads}

A 4-point bending setup was manufactured from Inconel 718 material in order to resist high temperatures at low thermal expansion without oxidation (see Figure 1). The length between the loading pins and the support pins was $8 \mathrm{~mm}$ and $16 \mathrm{~mm}$, respectively. Loading forces were applied manually to the bending setup using an adjustable screw to fix the crosshead. Normal force was recorded with a force dynamometer (Type 9254, Kistler Holding AG, Winterthur, Switzerland) underneath the bending setup. Thermal load was applied to the samples using ceramic heating elements (Glow igniters, Bach RC GmbH, Werneuchen, Germany) which could be tailored in various steps by a power regulator. With this setup thermal loads in the range of 500 to $800{ }^{\circ} \mathrm{C}$ could be applied to the samples depending on the heat capacity of the probe material. Temperatures on the sample 
surface were detected during the heating process using a two-color-pyrometer with a quartz fiber to inject thermal radiation (FIRE-3, RWTH, Aachen, Germany). Applied mechanical loads could be tailored in the measuring range of the dynamometer from $F=0 \mathrm{~N}$ to $1000 \mathrm{~N}$ resulting in bending stresses $\sigma_{B}$ dependent on the sample geometry according to the following equation:

$$
\sigma_{B}=\frac{3 \cdot F \cdot\left(l-l_{i}\right)}{2 \cdot b \cdot h^{2}}
$$

$b$ is the sample width, $h$ is the sample thickness, $l$ and $l_{i}$ are the length of the support span and the inner loading span, respectively [18]. Bending bars of mixed ceramic material with a composition of approximately $65 \mathrm{wt} \% \mathrm{Al}_{2} \mathrm{O}_{3}, 30 \mathrm{wt} \%$ $\mathrm{Ti}(\mathrm{C}, \mathrm{O})$, and $5 \mathrm{wt} \% \mathrm{ZrO}_{2}$ were fabricated according to standard procedure at the Hamburg University of Technology as described in previous works [19, 4]. Bending bars with dimensions of $\sim 3 \times 2.5 \times 35 \mathrm{~mm}^{3}$ were ground on all sides and additionally polished on the bottom side. Samples were put in the 4-point bending equipment and exposed to thermal and mechanical loads, which were applied separately or in combination for thermo-mechanical loads. Four different temperatures were applied to the samples and determined to be 490, 540, 600 and $670{ }^{\circ} \mathrm{C}$ for thermal loading. For mechanical testing different mechanical loads according to bending stresses from 100 to $600 \mathrm{MPa}$ were applied. For thermomechanical experiments mechanical loads from 100 to 300 MPa were applied simultaneously with a constant thermal load of $\sim 500^{\circ} \mathrm{C}$.

\subsection{Diffraction experiments}

The diffraction experiments were carried out at the High Energy Material Science (HEMS) beamline P07 of PETRA III (DESY, Hamburg) using monochromatic synchrotron radiation with an energy of $\sim 87 \mathrm{keV}$, corresponding to a wavelength of $\lambda=0.0143 \mathrm{~nm}$. The beam size was set to $0.2 \times 0.2 \mathrm{~mm}^{2}$ using a high precision slit system ${ }^{1}$. The sample was illuminated in transmission geometry according to the Debye-Scherrer method and diffraction patterns were recorded with a flat panel detector (Figure 2) [20]. For detector details see Table 1. The setup was

\footnotetext{
${ }^{1}$ Optics consist of two flat water-cooled Laue crystals Si(111) and Si(220) 15 x 30 x $1.5 \mathrm{~mm}$ in dimensions, with an asymmetric angle of $35.36^{\circ}$. For an incoming energy of $87 \mathrm{keV}$, the $\mathrm{Si}(220)$ crystal was placed into the white synchrotron radiation beam.
} 
mounted onto a stage which could be moved in $\mathrm{x}$ - and $\mathrm{y}$-direction for alignment of the samples in the incident synchrotron beam. Measuring points were placed in the middle of the bending sample along the y-axis in intervals of $0.2 \mathrm{~mm}$. Calibration of the wavelength was done by measuring zinc powder as reference. Diffraction experiments were carried out in situ during thermal, mechanical, and thermo-mechanical loading of the mixed ceramic samples as described above. For reference of the load free state, samples were always measured in advance without application of any load.

\subsection{Data evaluation}

Integration of the diffraction patterns was done in different directions using A2tool software, version 0.23a (A. Rothkirch, Hasylab, DESY). Diffraction spectra were evaluated using the tool Fityk by fitting the two main peaks for each phase with a Voigt function [21]. Lattice parameters for the strain calculation were determined according to Bragg's law:

$$
\lambda=2 d \sin \theta_{\text {Voigt }}
$$

$\theta_{\text {Voigt }}$ is the Bragg scattering angle at peak maximum obtained from Voigt fit, $\lambda$ is the wavelength of the incident beam, and $d$ is the lattice constant [22]. Thus, for the two main phases the lattice constants where determined, i.e. $d_{113}$ and $d_{116}$ for alumina $\left(\mathrm{Al}_{2} \mathrm{O}_{3}\right)$ and $d_{111}$ and $d_{200}$ for titanium oxycabide ( $\mathrm{Ti}(\mathrm{O}, \mathrm{C})$ ), respectively. Identification of the phases was done by comparing the patterns with the following JCPDS-Standards: 00-010-0173 $\left(\mathrm{Al}_{2} \mathrm{O}_{3}\right)$, 03-065-8804 (TiC), and 01086-2352 (TiO).

Elastic strains $\varepsilon$ were derived by differentiating Bragg's law at a constant wavelength according to the following equation [22]:

$$
\varepsilon=\frac{d-d_{0}}{d_{0}}=-\cot \theta_{0} \Delta \theta
$$

$d$ is the lattice parameter of each phase, $d_{0}$ is the lattice parameter of the according phase in the reference sample, $\theta$ is the scattering angle of each phase, and $\theta_{0}$ is the scattering angle of the according phase in the reference sample. In order to receive the different strain tensor components, $\varepsilon_{11}$ and $\varepsilon_{22}$, scattering angles were 
determined from integration of the spectra in $x$ - and y-direction (see Figure 2). To improve the signal-to-noise ratio, spectra were recorded over circle segments from $-10^{\circ}$ to $+10^{\circ}$ in each direction.

\section{Results and Discussion}

The experimental setup described above turned out to be suitable for applying thermal and mechanical loads to mixed ceramic samples in situ during X-ray diffraction with synchrotron radiation. Strain tensor components could be measured with a precision of $\Delta \theta=0,3 \cdot 10^{-6} \mathrm{rad}$ and accordingly $\Delta \varepsilon \approx 10^{-5}$ which means that accuracy is sufficient to determine shifts of lattice parameters in the diffraction spectra due to external loads on the sample.

Data obtained from temperature experiments at room temperature for reference and at a thermal load of $\sim 500{ }^{\circ} \mathrm{C}$ are shown in Figure 3. At room temperature, alumina $\left(\mathrm{Al}_{2} \mathrm{O}_{3}\right)$ shows constant lattice parameters over the whole sample height whereas in titanium oxycarbide $(\mathrm{Ti}(\mathrm{O}, \mathrm{C}))$ lattice parameters vary over sample height indicating variations in stochiometric composition of the $\operatorname{Ti}\left(\mathrm{O}_{\mathrm{x}}, \mathrm{C}_{\mathrm{y}}\right)$-mixed crystal from the reaction sintering process. The asymmetric behavior of the stoichiometric variation is due to preparation of the bending bar which is done by grinding and polishing of the lower surface and only grinding of the upper surface. Thus, more material is removed on the bottom side of the sample. The inner part of the sample shows almost pure titanium carbide (TiC) which has a lattice spacing of $d_{111}=2.49531 \AA$ in accordance with JCPDS data No. 03-0658804. In the outer parts of the sample more and more oxygen is incorporated in the TiC-lattice, thus shifting the lattice spacing to slightly lower values in the direction of titanium(II)oxide ( $\mathrm{TiO}$ ) with a lattice parameter of $d_{111}=2.47856 \AA$ in accordance with JCPDS data No. 01-086-2352. Results at an elevated temperature of $\sim 500{ }^{\circ} \mathrm{C}$ show that lattice spacings shift to higher values due to thermal expansion of the mixed ceramic sample. Also, a gradient in temperature is apparent in both phases indicating a slight increase in temperature from the highest to the lowest measuring position on the sample. This gradient in temperature is due to a non-uniform thermal flux over the sample height caused 
by the asymmetric setup of inner loading spans and support spans in horizontal direction.

Results from temperature experiments show linear peak shifts and a linear behavior of the lattice strains with increasing temperature from 480 to $670{ }^{\circ} \mathrm{C}$ for the two main phases of the mixed ceramic (see Figure 4). It becomes evident that the $\operatorname{Ti}(\mathrm{O}, \mathrm{C})$-phase shows about $~ 10 \%$ higher thermal expansion of the lattice constant than the $\mathrm{Al}_{2} \mathrm{O}_{3}$-phase. From the slopes of the curves in Figure 4, a coefficient of linear thermal expansion in the range of 480 to $670{ }^{\circ} \mathrm{C}$ can be determined, i.e. $2.05 \cdot 10^{-6} 1 / \mathrm{K}$ for $\mathrm{Al}_{2} \mathrm{O}_{3}$ and $2.25 \cdot 10^{-6} 1 / \mathrm{K}$ for $\mathrm{Ti}(\mathrm{O}, \mathrm{C})$. According to Turner's approximation, a simple calculation can be done to determine the coefficient of thermal expansion $\alpha_{t h}$ for multi-phase materials [23]:

$$
\alpha_{t h} \approx \frac{\sum\left(\alpha_{i} \cdot K_{i} \cdot V_{i}\right)}{\sum\left(K_{i} \cdot V i\right)}
$$

$\alpha_{i}$ is the coefficient of thermal expansion and $V_{i}$ the phase content of each phase. $K$ is the bulk modulus and can be calculated from the Young's modulus $E$ and Poisson's ratio $v$ :

$$
K=\frac{E}{3(1-2 v)}
$$

Thus, a coefficient of thermal expansion for the mixed ceramic material of $\alpha_{t h}=2.12 \cdot 10^{-6} 1 / \mathrm{K}$ can be determined (see Table 2 for materials properties). For comparison, the macroscopic thermal expansion was measured using a dilatometer type DIL 402 PC/4 (Nertzsch-Gerätebau GmbH) in the range of 50 to $900{ }^{\circ} \mathrm{C}$ with a heating rate of $3 \mathrm{~K} / \mathrm{min}$ in air. A coefficient of linear thermal expansion of $\alpha_{t h}=2.25 \cdot 10^{-6} 1 / \mathrm{K}$ was determined for mixed ceramic samples. This result is in good agreement with the thermal expansion of the different phases calculated from the slope of the graph of lattice strain versus temperature in Figure 4. Therefore, the following conclusions can be drawn: during reaction sintering the mixed ceramic material is in a stress free state. Upon cooling, thermal stresses from the difference in the coefficients of thermal expansion of the two main phases must evolve. At room temperature this would cause compressive stresses in the $\mathrm{Al}_{2} \mathrm{O}_{3}$-phase due to a lower coefficient of thermal expansion and tensile stresses in the $\mathrm{Ti}(\mathrm{O}, \mathrm{C})$-phase due to a higher coefficient of thermal expansion. In general, with a simple calculation using Hooke’s law, a difference 
in lattice strain of the two phases of $\Delta \varepsilon \approx 10^{-4}$ would imply an internal stress of $\sigma=\Delta \varepsilon \cdot E \approx 40 \mathrm{MPa}$ in the mixed ceramic material.

Results from 4-point-bending show compression on the upper side and tension on the lower side of the bending sample. Thus, the differences in lattice strains from compression and tension in the bending bar can be detected because of a high special resolution with a beam size of only $0.2 \times 0.2 \mathrm{~mm}$. In Figure 5 the elastic lattice strain $\varepsilon_{11}$ in the highest and lowest measuring position on the sample is shown as a function of the applied bending stress $\sigma_{B}$. Additionally, lattice strain due to bending stress in combination with a thermal load of $500{ }^{\circ} \mathrm{C}$ is also shown in Figure 5. Lattice strains due to bending are equal for both phases and in all crystallographic directions. Small deviations in the lattice strains of the $\mathrm{Ti}(\mathrm{O}, \mathrm{C})$ phase at high compression are due to a measuring effect based on the stoichiometric composition of the $\operatorname{Ti}(\mathrm{O}, \mathrm{C})$ (see Figure 3). With increasing deflection of the bending bar in relation to the unbent reference sample this measuring effect increases. By applying also thermal load to the bended sample both the compression and the tension curve shift to higher lattice strains because of thermal expansion of the sample. From the elastic lattice strains, stress calculations of $\sigma_{11}$ and $\sigma_{22}$ could be done according to the following equation [22]:

$$
\sigma_{i j}=\frac{E}{1+v}\left[\varepsilon_{i j}+\delta_{i j} \frac{v}{1-2 v}\left(\varepsilon_{11}+\varepsilon_{22}+\varepsilon_{33}\right)\right]
$$

Lattice strain components $\varepsilon_{11}$ and $\varepsilon_{22}$ were determined from integration of the spectra in $\mathrm{x}$ - and $\mathrm{y}$-direction (see Figure 2). According to engineer's beam theory a plane strain state with zero elastic strain in z-direction $\left(\varepsilon_{33}=0\right)$ was assumed [25]. For values of Poisson's ratio and Young's modulus see Table 2.

Figure 6 und Figure 7 show the calculated stress states of $\mathrm{Al}_{2} \mathrm{O}_{3}$ - and $\mathrm{Ti}(\mathrm{O}, \mathrm{C})$ phases in $\sigma_{11^{-}}$and $\sigma_{22}$-direction versus applied bending stress $\sigma_{B}$ on the sample. Normal stresses in $\sigma_{11}$-direction show increasing internal stresses for both phases with increasing applied bending stress on the sample in the same order of magnitude. Lattice stresses in $\sigma_{22}$-direction are higher in $\mathrm{Al}_{2} \mathrm{O}_{3}$ than in $\mathrm{Ti}(\mathrm{O}, \mathrm{C})$ due to the difference in Poisson's ratio of the two phases. In general, in both directions, i.e. $\sigma_{11}$ and $\sigma_{22}$, internal stresses due to compression show slightly higher values than internal stresses due to tension. For further investigations residual stresses in the reference sample due to sample preparation should be determined in comparison to stress free powder. In conclusion, since there is 
almost no texture in the sample and elastic anisotropy is very low, a homogeneous strain state develops in both phases of the mixed ceramic upon mechanical loading. Calculated stresses from elastic lattice strains are also very similar for both phases due to similar elastic constants of $\mathrm{Al}_{2} \mathrm{O}_{3}$ and $\mathrm{Ti}(\mathrm{O}, \mathrm{C})$.

\section{Summary and Conclusions}

A first experimental setup was presented to determine internal stress states in the different phases of mixed ceramics $\left(\mathrm{Al}_{2} \mathrm{O}_{3}-\mathrm{Ti}(\mathrm{O}, \mathrm{C})\right)$ in situ during application of thermal, mechanical, and thermo-mechanical loads. By using high-energy synchrotron radiation for X-ray diffraction, an accuracy of the whole setup of $\Delta \varepsilon=10^{-5}$ could be achieved. Shifts in lattice parameters of the different phases could be determined due to different external loads. All lattice strains were referred to samples without application of any external load. From measuring results at room temperature it can be concluded that the $\mathrm{Ti}(\mathrm{O}, \mathrm{C})$ phase exhibits a gradient in stoichiometric composition such that the inner part of the sample consists of almost pure titanium carbide ( $\mathrm{TiC}$ ) with growing oxygen content in the TiC-lattice to the sample surface. By application of external thermal loads to the mixed ceramic the $\mathrm{Al}_{2} \mathrm{O}_{3}$-phase showed a slightly lower coefficient of thermal expansion than the $\mathrm{Ti}(\mathrm{O}, \mathrm{C})$-phase. This leads to the fact that upon cooling from the sintering temperature $\mathrm{Al}_{2} \mathrm{O}_{3}$ suffers compression whereas $\mathrm{Ti}(\mathrm{O}, \mathrm{C})$ suffers tension in the mixed ceramic material. With a simple calculation using Hooke's law an internal stress of $\sim 40 \mathrm{MPa}$ could be estimated. The results from 4-pointbending show that elastic lattice strains could be determined separately for each phase, and the material's behavior is in accordance to Voigt, i.e. elastic strains are equal in all crystallographic directions and in both phases. Calculated internal stresses in $\sigma_{11}$-direction showed values in the same order of magnitude as external bending stresses for both phases. In order to get a better understanding of wear mechanisms of mixed ceramic cutting tools internal stress states should be determined under more complex loads. Thus, further experiments will be carried out under real conditions in situ during friction and turning tests in the future. 


\section{References}

[1]

[5]

[6]

[8]

[9]

Uhlmann E, Richarz S, Oyanedel Fuentes JA (2011) Hartdrehen von PMSchnellarbeitsstahl. Diam Bus 1:10-19

Ophey, L (1998) Trockenbearbeitung. Bearbeitung metallischer Werkstoffe ohne Kühlschmierstoffe. Expert, Renningen-Malmsheim

Kumar AS, Durai AR, Sornakumar T (2006) Wear behaviour of alumina based ceramic cutting tools on machining steels. Tribol Int 39:191-197

Bhattacharya AK, Zimmermann K, Schneider GA, Hintze W (2008) Influence of surface modification on the cutting performance of reaction-sintered $\mathrm{Al}_{2} \mathrm{O}_{3}$-TiOC ceramics. J Am Ceram Soc 91:2982-2986

Cakan A (2011) Real-time monitoring of flank wear behavior of ceramic cutting tool in turning hardened steels. Int J Adv Manuf Tech 52:897-903

Dureja JS, Gupta VK, Sharma VS, Dogra, M (2010) Wear mechanisms of coated mixed-ceramic tools during finish hard turning of hot die steel. J Mech Eng Sci 224:183-193

Singh D, Rao PV (2010) Flank wear prediction of ceramic tools in hard turning. Int J Adv Manuf Techol 50:479-493

Pfeiffer W, Frey T (2006): Strengthening of ceramics by shot peening. J Eur Cer Soc 26:2639-2645

Vogli E, Tillmann W, Selvadurai-Lassl U, Fischer G, Herper J, (2011) Influence of Ti/TiAlN-multilayer designs on their residual stresses and mechanical properties. Appl Surf Sci 257:8550-8557

Jianxin D, Zhenxing D, Dongling Y, Hui Z, Xing A, Jun Z (2010) Fabrication performance of $\mathrm{Al}_{2} \mathrm{O}_{3} /(\mathrm{W}, \mathrm{Ti}) \mathrm{C}+\mathrm{Al}_{2} \mathrm{O}_{3} / \mathrm{TiC}$ multilayered ceramic cutting tools. Mater Sci Eng A 527:1039-1047

Deng JX, Yun DL, Zhou HM, Tan YQ (2012) Layered structures in ceramic nozzles for improved erosion wear resistance in industrial coal-water-slurry boilers. Ceram Int 36:299-306

Hussainova I, Kolesnikova A, Hussainov M, Romanov A (2009) Effect of thermo-elastic residual stresses on erosive performance of cermets with core-rim structured ceramic grains. Wear 267:177-185

Bartolomé JF, Aza AH, Martín A, Pastor JY, Llorca J, Torrecillas R, Bruno G (2007) Alumina/zirconia micro/nanocomposites: a new material for biomedical applications with superior sliding wear resistance. J Am Ceram Soc 90:31773184

Gibmeier J, Hartmann S, Scholtes B (2005) Effect of applied and residual stresses on the analysis of mechanical properties by means of instrumented indentation techniques. Mater Sci Forum 490-491:454-459

Waikar RA, Guo YB (2007) Residual stress evolution and mechanical state of hard machined components in sliding contact. Tribol Trans 50:531-539 
Kurt A, (2009) Modelling of the cutting tool stresses in machining of Inconel 718 using artificial neural networks. Expert Syst Appl 36:9645-9657 Fitzpatrick ME, Hutchings MT, Withers PJ (1997) Separation of macroscopic, elastic mismatch and thermal expansion misfit stresses in metal matrix composite quenched plates from neutron diffraction measurements. Acta Mater 45:48674876 DIN EN 843-1 (2008) Hochleistungskeramik - Mechanische Eigenschaften monolithischer Keramik bei Raumtemperatur - Teil 1: Bestimmung der Biegefestigkeit. Beuth, Berlin

[19] Zimmermann K, Schneider GA, Bhattacharya AK, Hintze W (2007) Surface modification of $\mathrm{Al}_{2} \mathrm{O}_{3} / \mathrm{TiC}$ cutting ceramics. J Am Ceram Soc 90:3773-3778 He BB (2009) Two-dimensional x-ray diffraction. Wiley, Hoboken Wojdyr M (2010) Fityk: A general-purpose peak fitting program. J Appl Cryst 43:1126-1128

Rohrbach C, Ahrensdorf K (1989) Handbuch für experimentelle Spannungsanalyse. VDI, Düsseldorf Salmang H, Scholze H (2007) Keramik. Springer, Berlin Eigenmann B (1992) Röntgenographische Analyse inhomogener Spannungszustände in Keramiken, Keramik-Metall-Fügeverbindungen und dünnen Schichten. Dissertation Karlsruhe University Schnell W, Gross D, Hauger W (1998) Technische Mechanik. Springer, Berlin 
Table 1: Details of the 2D flat panel detector (Perkin Elmer XRD 1622 AO, USA).

\begin{tabular}{ll}
\hline Pixel size & $200 \times 200 \mu \mathrm{m}^{2}$ \\
Number of pixels & $2048 \times 2048$ \\
Absolute size of detector & $410 \times 410 \mathrm{~mm}^{2}$ \\
Distance sample to detector & $2000 \mathrm{~mm}$ \\
Exposure time & $7 \mathrm{~s}$ \\
Signal-to-noise ratio & $1000: 1$ \\
\hline
\end{tabular}

Table 2: Overview on properties of the two main phases of the mixed ceramic material $[24,18]$.

\begin{tabular}{lll} 
Phase material & $\mathrm{Al}_{2} \mathrm{O}_{3}$ & $\mathrm{TiC}$ \\
\hline Young's modulus [GPa] & 387 & 435 \\
Poisson's ratio [-] & 0.25 & 0.20 \\
Phase content [-] & 0.65 & 0.35 \\
\hline
\end{tabular}




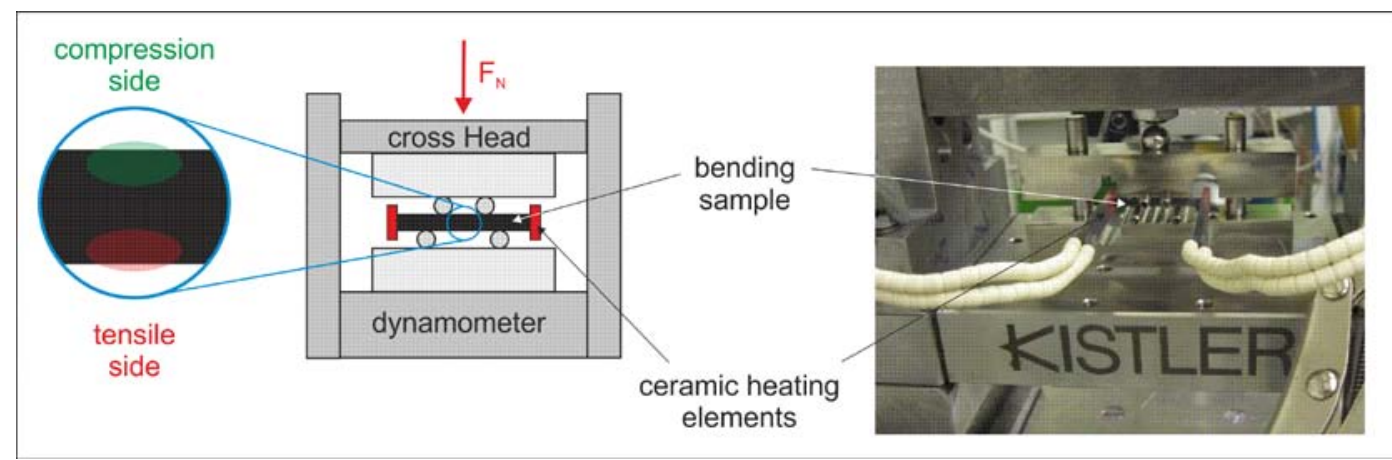

Figure 1: Setup for the application of thermal and mechanical loads.

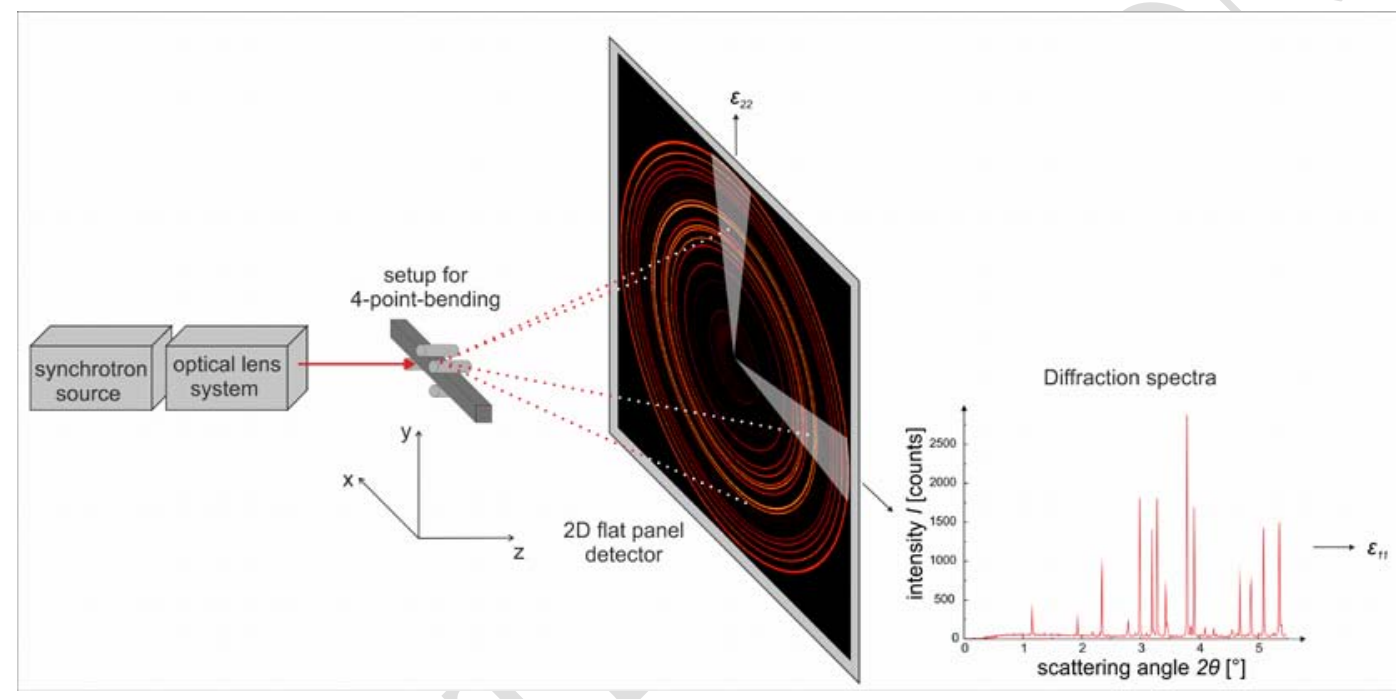

Figure 2: Sketch of the setup for diffraction experiments at the HEMS beamline P07 of PETRA

III.

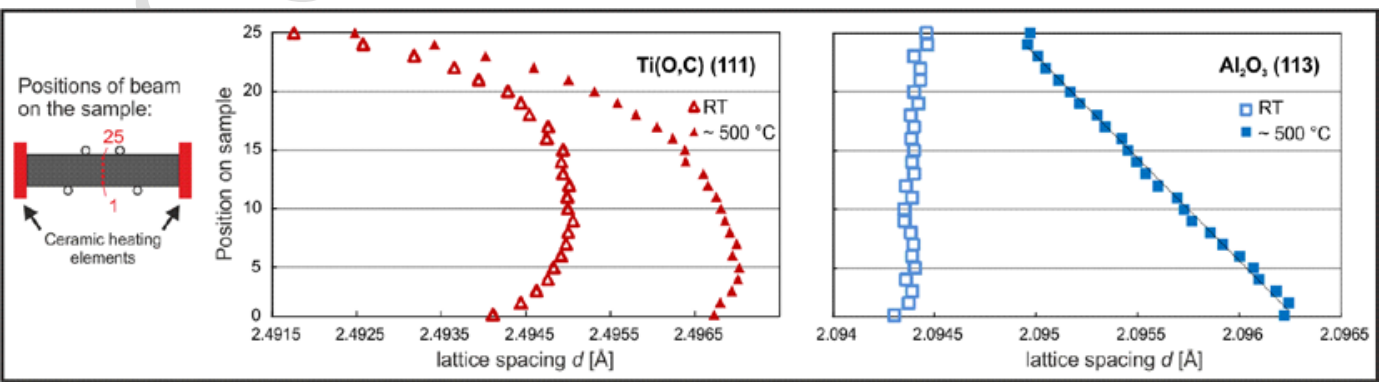

Figure 3: Lattice parameters of the two main phases $\left(\mathrm{Ti}(\mathrm{O}, \mathrm{C})\right.$ and $\left.\mathrm{Al}_{2} \mathrm{O}_{3}\right)$ across the sample height in vertical direction at room temperature (RT) and at $\sim 500{ }^{\circ} \mathrm{C}$. 


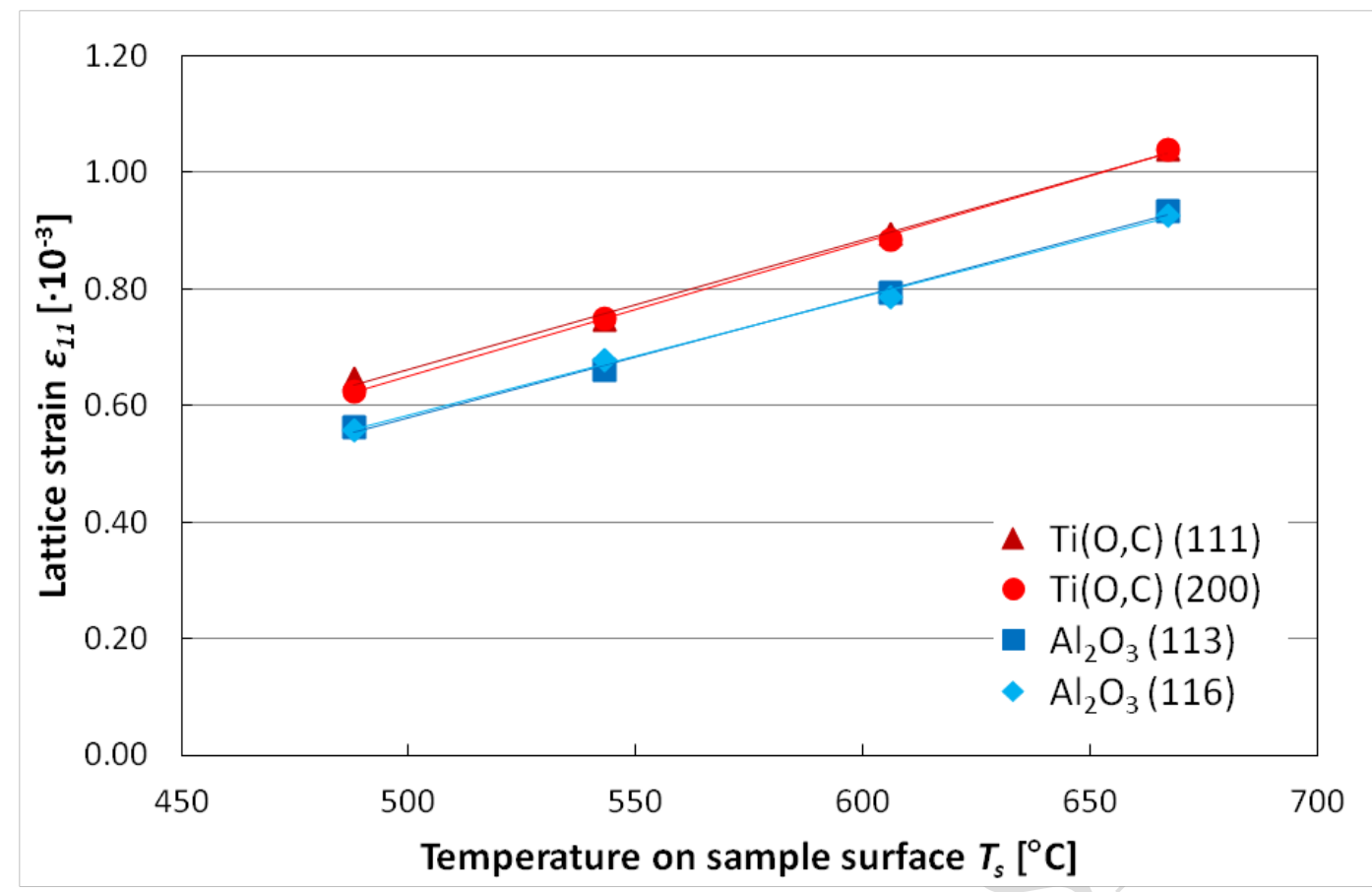

Figure 4: Elastic lattice strain for different phases of $\mathrm{Ti}(\mathrm{O}, \mathrm{C})$ and $\mathrm{Al}_{2} \mathrm{O}_{3}$ at elevated temperatures.

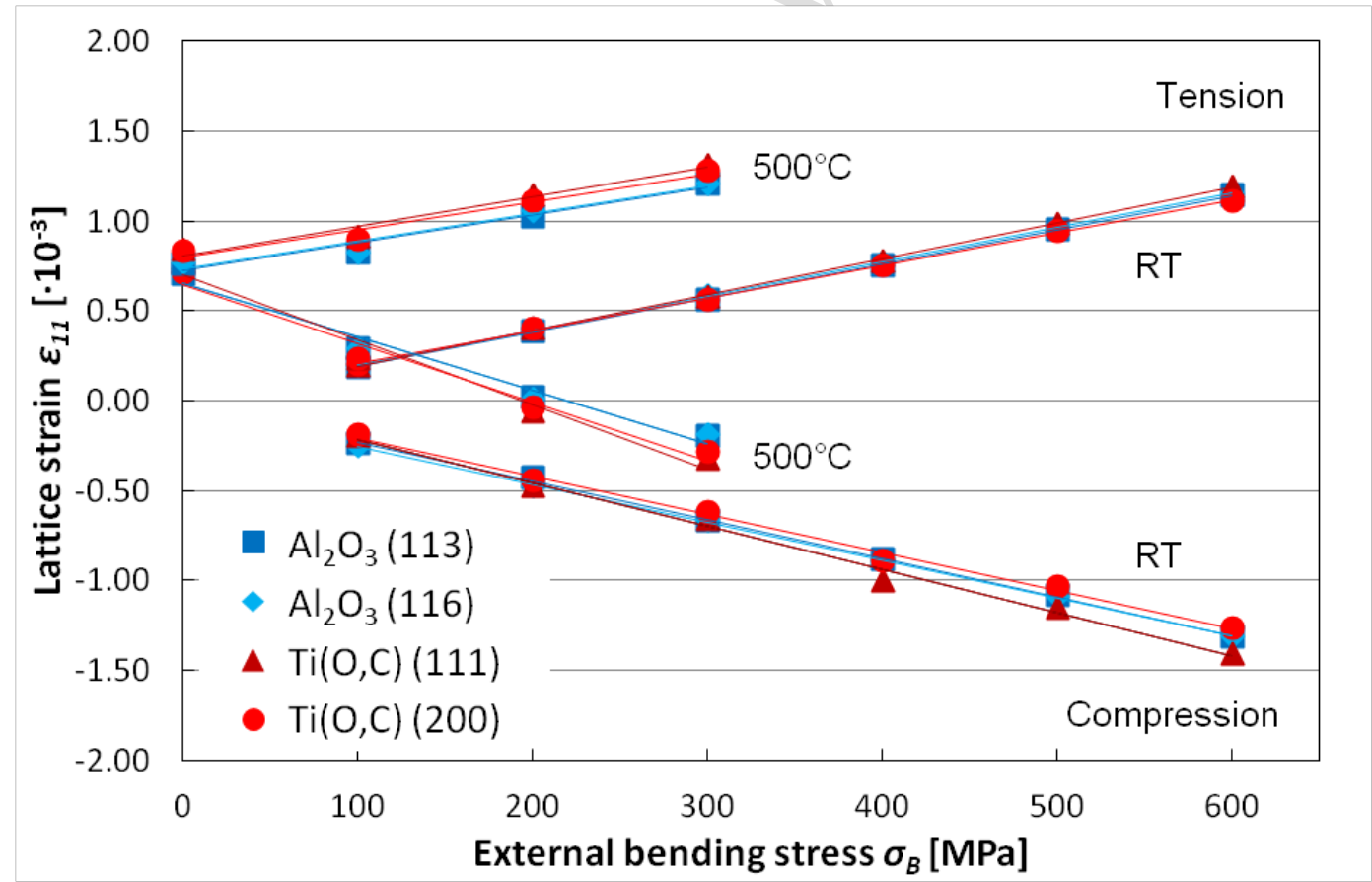

Figure 5: Lattice strain $\varepsilon_{11}$ in the different phases versus bending stress on the sample is shown during 4-point bending at room temperature and at elevated temperature. 


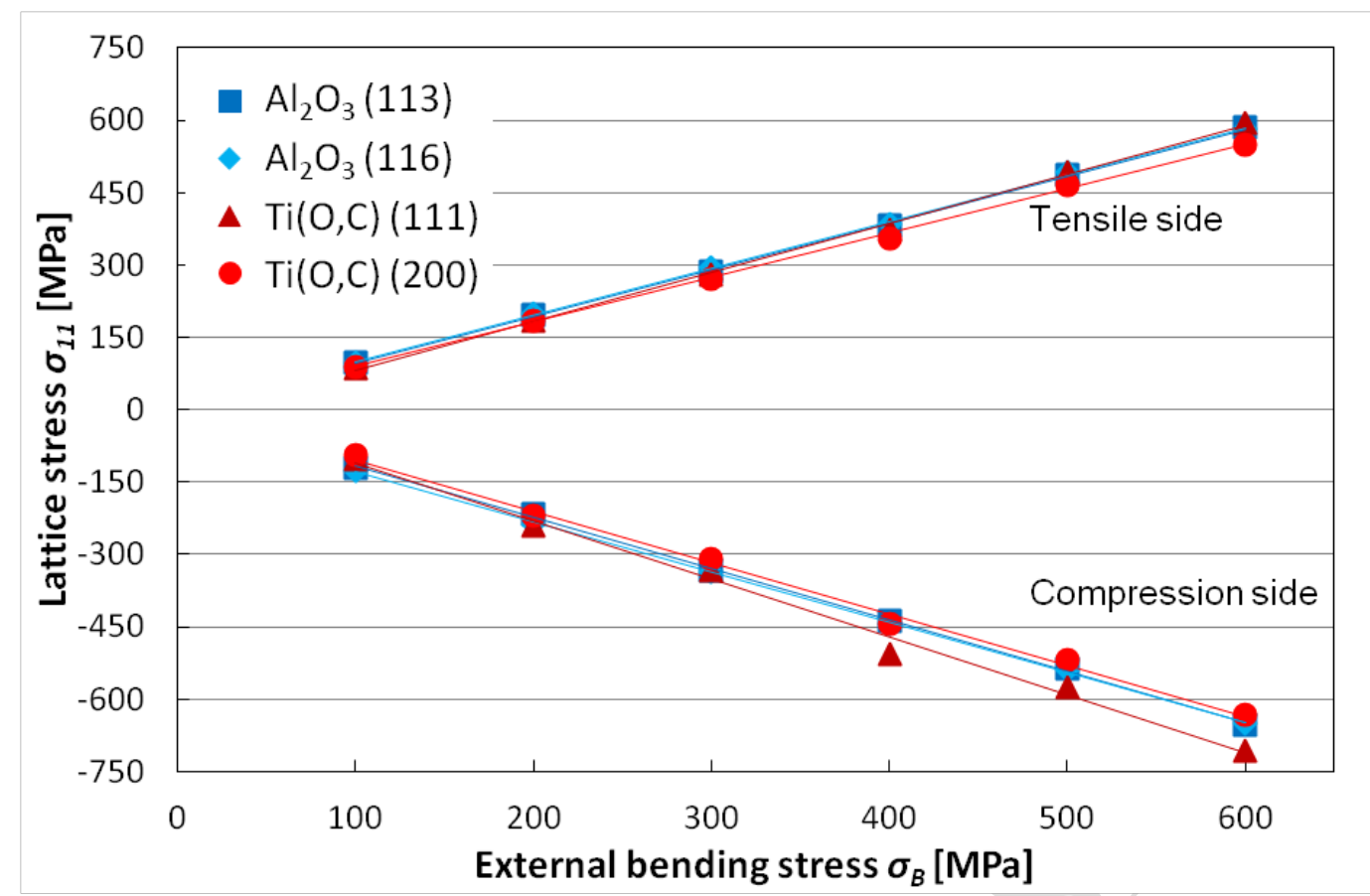

Figure 6: Normal stress $\sigma_{11}$ (in direction of bending stress $\sigma_{B}$ ) for the two phases versus bending stress acting on the mixed ceramic material.

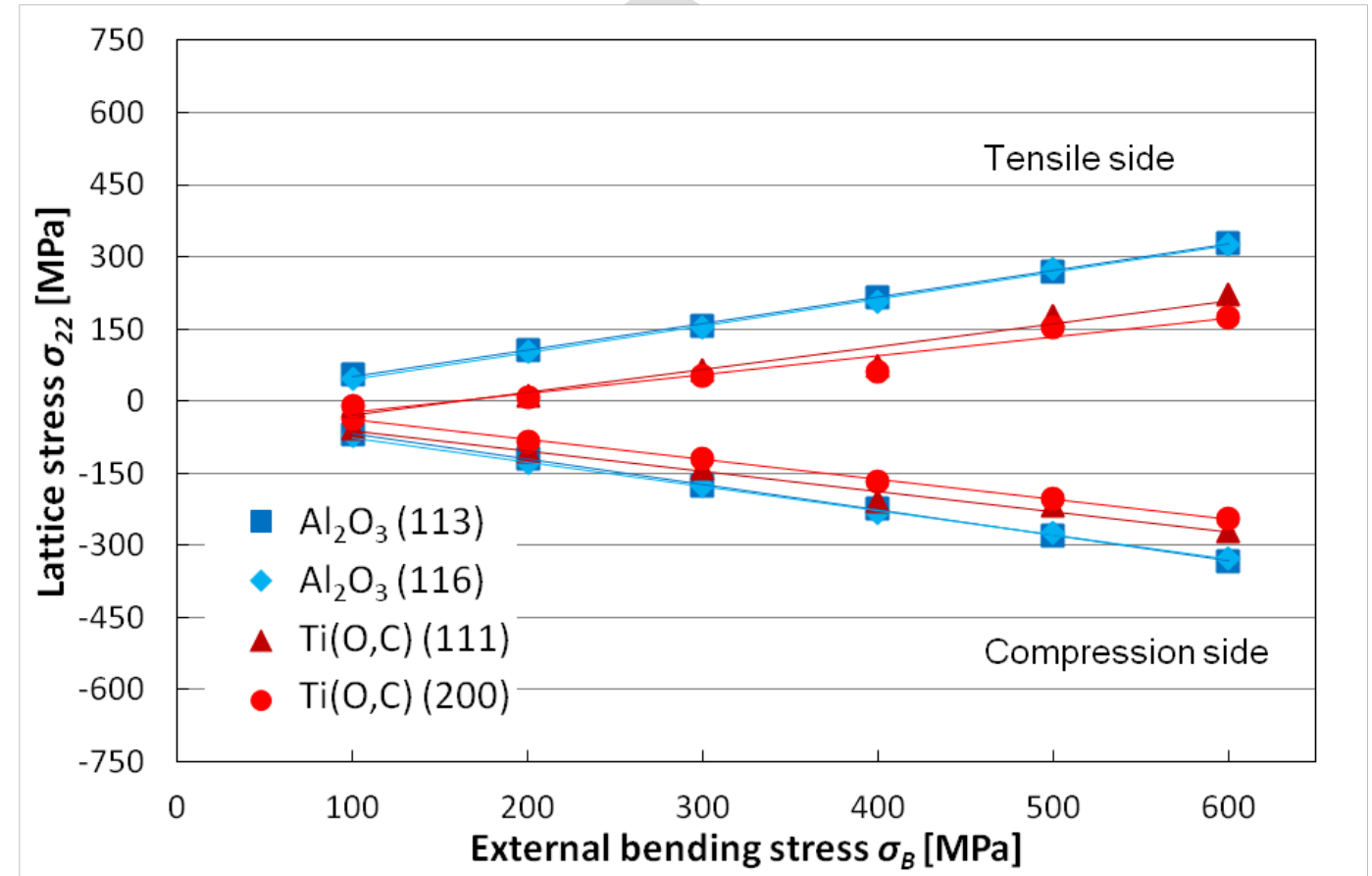

Figure 7: Normal stress $\sigma_{22}$ (perpendicular to bending stress $\sigma_{B}$ ) for the two phases versus bending stress acting on the mixed ceramic material. 